\title{
Representações de Morte e Recomeço na Literatura Infantil de Josué Guimarães
}

Pedro Afonso Barth*

\section{Resumo}

A última bruxa, instigante e provocativa obra infantil de Josué Guimarães, foi publicada em 1987. Por meio da mobilização da figura da bruxa, Guimarães cria uma história que dialoga com conceitos como morte, vida, eternidade, velhice e recomeço. O objetivo deste trabalho é analisar a obra citada percebendo como as dicotomias morte $\mathrm{x}$ vida, fim $\mathrm{x}$ recomeço são fundamentais para a compreensão da narrativa. Defendemos nesse trabalho, que a obra apresenta três possibilidades de interpretação; uma alinhada às vivências do leitor infantil - e assim, a história será uma reinterpretação de contos de fadas. Outra que leva em conta o contexto de produção e assim a obra pode ser lida como uma analogia para a abertura democrática brasileira no final dos 1980. E finalmente, uma terceira leitura, que compreende as referências à magia como metáforas para a própria existência humana na Terra - e assim "A última Bruxa” é uma aguda narrativa sobre o sentido da vida.

Palavras-chave: Literatura Infantil. Josué Guimarães. Bruxa. Morte.

\section{Introdução}

Josué Guimarães tem como marca na sua atuação como escritor o fato de sempre estar conectado com as demandas de seu tempo. Isso não é perceptível apenas nas temáticas e diálogos estabelecidos pelos seus textos ficcionais, mas também ao observarmos as suas escolhas editoriais. É um autor engajado no pleno sentido da palavra, que fez da sua obra uma arte preocupada em despertar cons-

\footnotetext{
Doutor em Letras pela Universidade Estadual de Maringá (UEM $\backslash 2019$ ). Mestre em Letras pela Universidade de Passo Fundo (UPF/2016) na linha de Leitura e Formação do Leitor cuja dissertação foi dedicada à pesquisa de Sagas Fantásticas, especialmente Crônicas de Gelo e Fogo. Especialista em Língua Portuguesa Novos Horizontes Teóricos e Práticos (UPF - 2013) e pesquisou Letramento digital e multimodalidade nas redes sociais. Possui graduação em Letras (Língua Portuguesa e Língua Espanhola e respectivas literaturas) pela Universidade de Passo Fundo (UPF/2012). É pesquisador no Grupo do CNPq "FORPROLL: Formação de Professores de Línguas e Literatura" e aluno pesquisador no grupo CNPq "CELLE- Centro de Estudos de Literatura, Leitura e Escrita: História e Ensino". Atua principalmente nos seguintes temas: Literatura Juvenil Brasileira Contemporânea, Sagas Fantásticas, Letramento, Multimodalidade, Ensino de Língua Portuguesa, Ensino de Literatura, Formação de Leitores, Literatura Infantil e Literatura Hispano-americana. E-mail: pedroabarth@hotmail.com
}

Data de submissão: ago. 2021 - Data de aceite: out. 2021

http://dx.doi.org/10.5335/rdes.v17i3.12786 
ciências e denunciar injustiças. Nesse sentido, destacamos a sua atuação como agente de respaldo das jornadas literárias de Passo Fundo, o que viabilizou sua existência no início da década de 1980. Foi justamente nessa época que passa a produzir obras literárias endereçadas para o público infantil e para o público juvenil, denotando uma genuína preocupação com a formação de leitores. Dentre essas obras, destacamos A última bruxa, instigante e provocativa obra infantil de Josué Guimarães, publicada postumamente, no ano de 1987. Trata-se uma narrativa que dialoga com os contos de fadas, com histórias de fantasia e é cheia de simbolismos e metáforas.

A protagonista da história, aquela que será a última bruxa enunciada no título, é Vovozinha, uma já anciã de 221 anos que vive no alto de uma enorme torre, isolada e sem poderes. Seu único consolo é saber que é a bruxa mais horrorosa que há no mundo - afirmação repetida por seu espelho mágico. O que a bruxa não imagina é que ela é a mais feia pelo simples fato de ser a única bruxa ainda viva no mundo. Vovinha tem a grande frustração de não ter poderes, de não conseguir fazer o que as bruxas deveriam fazer: como voar com a sua vassoura em meio às criaturas da noite. Ao tentar encontrar seus poderes, constata que não tem uma feia verruga em seu nariz e conclui que essa é a razão de não conseguir criar magias e encantamentos.
Durante o processo de descobrir uma poção em busca da verruga e de seus poderes, a personagem faz descobertas impressionantes que a obrigam a sair da torre em que vivia nos últimos trezentos anos. Ao descer da torre, Vovozinha conhece o mundo moderno e enfrenta uma realidade que não imaginava ser possível: o mundo moderno. Ao mesmo tempo que encontra sua magia, descobre que precisa correr contra o tempo e transferir os poderes mágicos para uma criança, antes de desaparecer com o sopro do vento.

Por meio da mobilização da figura da bruxa, Guimarães cria uma história que dialoga com conceitos abstratos e profundos como morte, vida, eternidade, velhice e posteridade. Consideramos que a obra possibilita vários planos ou possibilidades de interpretação. O objetivo deste trabalho é analisar a obra citada percebendo como as dicotomias morte $\mathrm{x}$ vida, fim x recomeço são fundamentais para a compreensão da narrativa, permitindo assim, relacionar pelo menos três possibilidades de leitura da obra.

Para tanto, na primeira seção, apresentamos que a obra A última Bruxa e a composição dos seus quatro capítulos. Em seguida, apresentamos duas possibilidades de interpretação da obra: uma leitura à esteira do maravilhoso e outra levando em conta o contexto de produção. A terceira será melhor detalhada na última seção, intitulada Morte, esquecimento e renovação em A última Bruxa. 


\section{A última narrativa infantil de Josué Guimarães}

Josué Guimarães publicou várias obras endereçadas ao público infantil. Por suas características temáticas e estruturais podem ser classificadas em três grupos (AGUIAR, 1997). O primeiro, composto pelas obras A onça que perdeu as pintas (1984), História do agricultor que fazia milagres (1984) e $O$ avião que não sabia voar (1984), apresenta narrativas centradas em um contador de histórias, Tio Balduíno, que encanta seus sobrinhos com relatos absurdos e surpreendentes sobre pescarias e aventuras que flertam com o absurdo. $\mathrm{O}$ segundo grupo, por sua vez, apresenta narrativas que se organizam em torno de um grupo de crianças curiosas, que reunidas, tentam resolver algum tipo mistério ou estão envolvidas em um entrecho de aventura e descobertas. É o caso de $A$ casa das quatro luas (1979), Xerloque da Silva em "O rapto da Dorotéia"(1982) e Xerloque da Silva em "Os ladrões da meia-noite" (1983).

O terceiro grupo diz respeito às histórias que vão dialogar intertextualmente com o universo dos contos de fadas, da fantasia e do insólito. Podem ser consideradas como contos do maravilhoso. Nestas obras, os elementos encadeadores da narrativa serão seres de fantasia, como uma bruxa ou um dragão. Com essas características podemos listas Era uma vez um reino encantado (1980), Meu primeiro dragão (1983) e A última bruxa (1987). Esta última, publicada postumamente, nos interessa especialmente neste trabalho, já que apresenta complexidade temática.

A última Bruxa apresenta quatro curtos capítulos. No primeiro, há a introdução da personagem, sua decadência e seu desajuste como uma típica bruxa são descritos. A história é apresentada de forma que o leitor infantil vai reformular o conceito do que é ser bruxa, já que Vovozinha apresenta uma certa quebra de estereótipos: é feia como uma bruxa, mas não tem poderes, tem vassoura e espelho, mas não sente impulsos de maldade. $\mathrm{E}$ por não corresponder ao que seria o perfil ideal de bruxa, a personagem sofre. Assim, o aniversário que poderia ser um momento de alegria, passa a ser um momento de reflexão e tristeza, pois Vovozinha percebe que a despeito de suas roupas puídas, e de sua feiura, ela não possui poderes característicos de uma bruxa.

Entretanto, a não-correspondência com a imagem medieval de uma bruxa malvada, é um grande conflito para Vovozinha. Ela sofre ao não fazer maldades com o uso da magia, e sozinha no alto de uma torre que não para de cresce, busca razões para explicar a sua inabilidade como Bruxa. Assim, chega a uma conclu- 
são: ela não é uma bruxa perfeita pela ausência de um terrível e feia verruga na ponta de seu nariz.

O segundo capítulo trata justamente da busca de Vovozinha pela sua verruga. Passam-se muitas décadas, e a bruxa fica em seu laboratório, trabalhando arduamente, tentando obter sucesso na criação de uma poção que faça nascer uma terrível verruga. Durante o trabalho, Vovozinha perde-se em recordações e desejos, principalmente recordações de sua mãe, ela sim, uma verdadeira bruxa. Assim, conversa com o espelho em busca de um interlocutor que possa ajudá-la a lidar com a saudade que sente e com a expectativa de conseguir realizar seus desejos - o desejo de ter poderes de bruxa, principalmente a habilidade de voar. Vovozinha passa noites e noites observando o voo de morcegos, projetando deles uma vontade adormecida, de poder pegar a sua vassoura e simplesmente atravessar os céus. $O$ capítulo termina com a bruxa, após anos de sacrifício, obtendo sucesso com uma das poções, e assim nasce uma verruga. Entretanto, mais uma vez, Guimarães brinca com as expectativas dos seus leitores, pois a verruga não está na ponta do nariz: está na ponta de seu dedo.

Nesse ponto, está estabelecida que a jornada da personagem não está relacionada com a projeção mais comum das bruxas em contos de fadas: como um ser invejoso que quer prejudicar uma bela princesa ou como um ser faminto que deseja possuir ou sumir com crianças. Em Josué Guimarães, a bruxa está numa jornada para entender e encontrar sua própria essência. Assim, não há um antagonismo de natureza maniqueísta na história, já que Vovozinha não é diretamente prejudicada por nenhum outro personagem, e nem faz maldades com ninguém.

Mesmo não correspondendo a imagem de uma verruga típica das bruxas, a nova verruga de Vovozinha passa a ser um motivo de alegria. E assim, principia o capítulo III, com a Bruxa sentindo-se corajosa por achar que agora tem poderes mágicos. Corajosamente pega sua vassoura e saí pela janela. Mas as coisas não acontecem conforme o planejado: apesar de sair toda alegre - inclusive cantando "Atirei um pau no gato-tô" - a vassoura não funciona e Vovozinha cai em uma queda livre do alto de sua torre. Ela só não se machuca, porque um bando de andorinhas veio ao seu socorro e ampararam a anciã com os seus bicos. Após o salvamento, ela é levada de novo ao alto da torre em que vive, e nesse momento fica desesperada por sua verruga não ter poderes.

É bastante significativo que a personagem principal do conto viva em uma enorme torre, praticamente prisioneira das circunstâncias. E ela também se relaciona diretamente com a passagem do tempo: a cada mês, a torre crescia um de- 
grau. O narrador até enuncia jocosamente: "portanto, a torre deve estar muito alta, se a gente multiplicar doze degraus por 221 anos. Quem souber que faça as contas" (GUIMARÃES, 1987, p. 6). A torre apresenta uma simbologia paradoxal (CHEVALIER; GHEERBRANT, 2012), pois ao mesmo tempo que representa uma ideia de elevação - já que a torre é uma estrutura que se ergue em direção aos céus - também pode representar uma prisão inacessível, que aprisiona e deixa o sujeito longe do mundo exterior. É o segundo sentido que é recuperado na história de Vovozinha, criando assim um diálogo com a torre de Rapunzel. Esta fica presa em uma enorme torre devido à interferência da antagonista do conto, bruxa que aprisiona. Aquela passa séculos em sua torre, mas sem um antagonismo visível. Sua prisão não é executada por um agente externo, não há um algoz que mantem Vovozinha prisioneira.

O afastamento da bruxa do convívio em sociedade pode ser contrastado com o isolamento das mulheres consideradas bruxas na história ocidental. Segundo Paola Zordan (2005, p. 337), mulheres consideradas bruxas eram vistas como ameaças, e eram frequentemente expulsas de suas aldeias, sendo assim

[...] a bruxa era isolada, uma fugitiva que, cedo ou tarde, seria procurada para servir como confessora de apaixonados e intermediar os mais diversos prodígios exigidos por aqueles que se arriscavam indo atrás de seus poderes.
Ou então, a bruxa era tirada do seu isolamento para ser julgada e condenada por seus atos. Porém, não é isso que acontece com Vovozinha: ninguém a procura em busca de feitiços, ninguém está caçando ou tem preocupação com ela. $\mathrm{O}$ isolamento da personagem é total.

Ao final do terceiro capítulo, acontece algo impensado para uma bruxa: Vovozinha deixa cair uma lágrima.

Seus olhos ardiam, custava a respirar e, finalmente, a sensação que uma lágrima lhe escorria pela face ressequida. Mas bruxa não chora, pensou de imediato, pelas dúvidas foi olhar-se no espelho. Mas era uma lágrima! [...] Voltou a examinar a verruga na ponta do dedo. Quem lhe poderia dar uma explicação para aquilo? Algo se passava, algo muito estranho. $\mathrm{O}$ pior de tudo é que ela própria não sabia de nada. Mesmo com a verruga no corpo, não sabia voar, não conseguia adivinhar coisa nenhuma, não sentia vontade de matar uma simples mosquinha, nem de arrancar as perninhas de uma simples barata. E como todo mundo sabe, bruxa adora fazer essas coisas (GUIMARÃES, 1987, p. 27-28).

No trecho anterior, podemos observar que o desespero por não ter poderes, faz com que Vovozinha chore pela primeira vez e mais do que isso, a personagem passa a ter uma espécie de crise de identidade. $\mathrm{E}$, nesse momento, a grande transformação da história acontece.

No quarto capítulo, o leitor entende a natureza da transformação: Vovozinha ao passar o seu dedo com a verruga pelo rosto começa a se transformar sua imagem: quando toca o seu nariz, ele deixa 
de ser curvado, quando toca seus feios cabelos, eles passam a ser sedosos, volumosos e lindos, e assim ela toda passa a se transformar, e ao final tem diante do espelho mágico, uma outra mulher jovem, linda, vestida como uma princesa, com direto até a ter sapatinhos de cristal. Ao ver sua imagem transformada, Vovozinha se sente feliz pela primeira vez e assim nasce uma vontade incontrolável de sair da torre e descobrir o mundo. E é isso que faz, desce os muitos degraus de sua torre, consegue passar pela enorme porta e vai de encontro ao mundo.

A personagem espera encontrar florestas, bosques, duendes e seres encantados. Mas encontra lixo, poluição, carros, cidade, paisagem urbana. Há uma confusão na mente da personagem que não entende os referentes do mundo que tem diante de si. E é no meio de tantas descobertas que lembra que tem uma missão: agora que descobriu sua própria magia, precisa passar ela adiante. Antes de sair da torre, o espelho mágico a advertiu que deveria encontrar uma menina para transmitir a magia. Então, vovozinha encontra em um parque uma linda bebezinha, passeando em um carrinho com sua mãe. Ao se aproximar da menina, toca seu rosto com o seu dedo, e a verruga transfere-se para o nariz da menina. E, nesse momento, um rápido vendaval chega e Vovozinha transforma-se em pó, e no ato derradeiro de sua existência, tem a consciência de ter sido a última bruxa.
A obra apresenta pelo menos três possibilidades de interpretação; uma alinhada às vivências do leitor infantil - que entenderá a história da última bruxa na face da terra como uma reinterpretação de contos de fadas; outra levando em conta o contexto de produção e as características gerais da obra de Josué Guimarães; e outra que percebe as referências à magia como metáforas para a própria existência humana na Terra - e assim "A última Bruxa" é uma aguda narrativa sobre o sentido da vida. Vamos descrever cada uma delas nas seções seguintes.

\section{Duas interpretações: à esteira do maravilhoso e ao contexto de produção}

A primeira possibilidade de interpretação é que está próxima do universo infantil - como é o propósito de uma obra endereçada para crianças, ter elementos reconhecíveis que promovem uma identificação por parte dos leitores. Imagens como Bruxas, torre, espelho mágico, poções, símbolos de magia, referências à contos como Rapunzel e Cinderela são elementos que criam relações intertextuais com contos de fadas e suas muitas representações midiáticas. Ou seja, há uma vinculação da história com a própria essência do gênero maravilhoso. Segundo Nelly Novaes Coelho (2000), está no gênero maravilhoso a fonte de nascimento da literatura: 
[...] desse maravilhoso nasceram personagens que possuem poderes sobrenaturais; deslocam-se, contrariando as leis da gravidade; sofrem metamorfoses contínuas (COELHO, 2000, p. 172).

Entretanto, na narrativa de Josué a forma que esses elementos tão conhecidos são conectados e reimaginados na narrativa cria uma configuração em que o imaginário que temos a respeito das bruxas é completamente reposicionado.

Isso porque a bruxa não inicia a história com poderes, e nem é capaz de nenhum deslocamento que contrarie as leis naturais. Ela é representada com um ser ordinário, vivendo a vida passivamente no alto de sua torre, apenas tendo lembranças sobre o poder das bruxas de sua família e lamentando não ser poderosa como sua mãe e avó. Dessa forma, concordamos com a análise que Sissa Jacoby faz sobre os novos significados que a figura da bruxa adquire na ficção de Josué Guimarães:

Vovozinha, na verdade, pode ser vista como uma metáfora da velha fantasia, presa ao imaginário ancestral que não encontra lugar, na contemporaneidade, fora dos contos folclóricos que a popularizaram. Tanto que não se reconhece como uma bruxa verdadeira, precisa tornar-se uma a partir do que rezam os "livros de família", receita pronta de bruxa autêntica (JACOBY, 2009, p. 9).

Assim, se levarmos em conta que Vovozinha é uma representação da imagem que as bruxas possuem nos contos de fadas, compreendemos que a falta de poderes e o seu (auto) exílio na torre acontecem por ela estar afastado dos elementos que a tornavam única $\mathrm{e}$ poderosa. A modernidade tira de Vovozinha o seu caráter mítico e assustador. Entretanto, o esvaziamento da magia não possui um caráter negativo, pois a personagem reencontra uma nova forma de magia, ao sair do seu espaço - descer da torre - e abraçar o mundo que não conhecia. Nessa perspectiva, o final do conto parece apontar uma reconfiguração do maravilhoso na modernidade: Vovozinha consegue transferir a magia para uma criança, e assim a magia pode permanecer nesse mundo.

Assim, esse primeiro plano de interpretação leva em conta a figura da bruxa e outros intertextos possíveis, que permitem interpretar a história como uma paródia/atualização dos contos de fadas. A desconstrução presente na identidade bruxa de Vovozinha é um ponto de interesse na obra, pois quando falamos em bruxas, séculos de imagens e narrativas sobre bruxas são mobilizadas. A imagem da mulher cruel, malévola, envelhecida, que odeia crianças e faz magias sempre com intenções negativas foi cristalizada pela tradição oral, e de certa forma espelha o medo que a sociedade ocidental sempre teve do feminino. Entretanto, a bruxa da obra de Guimarães rompe com essa representação e dialoga com outras bruxas presentes na literatura infantil brasileira, a partir dos 80 . 
Quando pensamos em um segundo plano de interpretação levamos em conta dois fatores: o contexto em que a obra foi produzida - metade da década de 80 , momento em que o Brasil saia efetivamente de um momento de forte repreensão e autoritarismo e iniciava o processo de redemocratização e as próprias características de Josué Guimarães, já que uma das marcas mais presentes na sua obra de Josué Guimarães foi a preocupação de repensar a história do Brasil a partir da ficção (RETTENMAIER, REMÉDIOS, 2006). Em todas as suas obras, é possível reconhecer um caráter de engajamento, uma expressão de seus ideais pessoais. Assim, é importante sempre considerar que

[...] esses ideais nortearam uma necessidade urgente de agir pela palavra, seja no jornalismo e na retórica de bancada partidária, seja como escritor. Assim, se essas três facetas, de político, de jornalista e de escritor, o caracterizam, a ação pela palavra eterniza Josué Guimarães, quanto mais em se tratando de um país como o Brasil (RETTENMAIER, VERARDI, 2019, p.11).

A partir disso, podemos enunciar a seguinte pergunta: é possível uma leitura contextualizada e política da última obra infantil publicada de Josué Guimarães? A resposta será positiva, pois vários elementos da história são alegóricos e possibilitam conexões com a realidade brasileira dos anos 80. Assim, Vovozinha pode representar a própria liberdade de expressão, que durante muitos anos ficou presa dentro de uma alta torre, que ape- nas crescia com o passar dos anos. Após um lento processo de maturação, ela decide sair da torre, derrubar a porta e conhecer o mundo. Como aponta Jacoby (2009, p. 90),

[...] encerrada na torre de um forte, Vovozinha perdeu a identidade e seus poderes. $\mathrm{O}$ pouco que restou - o sonho/fantasia indissociável do humano -, deve ser transmitido a uma criança, antes que $o$ vendaval transforme em pó a última bruxa.

Assim, depois de anos de reclusão, a magia pode sair da torre e foi transferida para uma criança - um símbolo de esperança e da possibilidade de futuro.

Há uma terceira possibilidade de leitura: uma interpretação que considera referências à magia como metáforas para a própria existência humana na Terra e assim "A última Bruxa" é uma aguda narrativa sobre o sentido da vida. Como essa leitura é mais insólita que as outras, vamos dedicar a próxima seção para o aprofundamento dessa perspectiva.

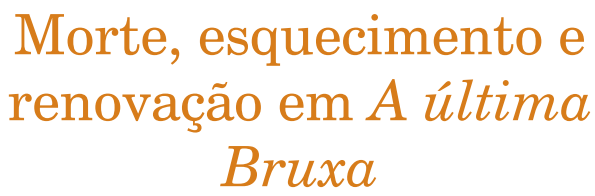

A terceira leitura interpretativa da obra de Josué considera as relações de vida e morte como condutores a narrativa. Nesse sentido, o título da obra é duplamente significativo, pois ele já traz duas informações que serão importantes: a identidade da personagem principal 
(ser bruxa) e o fato de ela ser a última de sua estirpe. São informações significativas, pois nas primeiras páginas do texto de Josué Guimarães, essas informações não aparecem, ficam implícitas e é a função do leitor relacionar o título com a narrativa. Podemos observar pela forma com a história inicia:

Era dia de aniversário de vovozinha. Fazia 221 anos. Como dizem as pessoas bem-educadas, Vovozinha completava 221 primaveras! Apesar disso ela jurava estar na flor da idade, pois sabia que seus antepassados chegavam muitas vezes aos quinhentos anos. E mais: não morriam como a gente. Iam ficando sequinhas, murchas e se acontecia de ventar muito, coisa assim de vendaval, se desfaziam em poeira e desapareciam para todo o sempre (GUIMARÃES, 1988, p. 5).

Na citação, já podemos observar a mobilização do aniversário, um ritual importante na cultura ocidental, que possui um caráter de ambiguidade: comemoramos a passagem do tempo, ou seja, celebramos o nosso envelhecimento, o que leva a uma única direção possível: a morte. A cada aniversário, estamos mais próximos do fim. Dessa forma, podemos apontar que o encontro com a finitude, com o final de uma jornada - especialmente marcado no título da obra por meio do adjetivo "última" - é um direcionamento da narrativa, já que logo em seguida já é descrita a maneira particular que uma bruxa morre: virando pó e desaparecendo no ar. Como já citado, o nome da personagem principal é Vovozinha, um nome que já apresenta e acentua a caracterização da personagem como alguém de idade avançada, além do uso do diminutivo, que acentua uma aura de afetividade e/ou fragilidade.

No trecho a seguir, podemos perceber que os últimos parágrafos da história infantil simplesmente narram a morte da personagem principal:

A mãe retornou, pediu licença e disse que estava na hora de levar a filhinha para casa. $\mathrm{E}$ antes que o carrinho se fosse, a bruxa e a mãe notaram que havia aparecido bem na ponta do narizinho da menina uma verruga cor-de-rosa do tamanho da ponta de um alfinete. $\mathrm{E}$ no minuto seguinte começou a ventar, nuvens negras baixaram dos céus, trovoadas e relâmpagos, correria de pessoas fugindo da tempestade repentina. [...] $\mathrm{E}$ aos poucos a ventania começou a levar o seu corpo, que se transformava em pó, exatamente como acontecia quando as bruxas chegavam na idade de morrer. Antes de sumir levada pelo vendaval, ela ficou sabendo que tinha sido a última bruxa da face da terra (GUIMARÃES, 1987, p. 38-40).

Isso, por si só, parece ser um rompimento com as expectativas de uma narrativa infantil, em que a projeção de um final feliz é esperada, especialmente porque o olhar adulto não admite que crianças possam conviver com desfechos trágicos e infelizes. Assim, a morte do protagonista em uma narrativa infantil parece extrema, até pelo imaginário sobre a morte presente no mundo ocidental, pois vivemos em um mundo que considera que a morte "designa o fim absoluto de qualquer coisa de positivo: um ser humano, um animal, uma planta" 
(CHEVALIER; GHEERBRANT, 2012, p. 621).

A morte vista como o fim de tudo está relacionando com o medo original, segundo Zygmunt Bauman. O medo original seria o maior de todos os medos, aquele que origina todos os pavores, isso porque "[...] nós, seres humanos, temos consciência da inevitabilidade da morte e assim também enfrentamos a apavorante tarefa de sobreviver à aquisição desse conhecimento - a tarefa de viver com o pavor da inevitabilidade da morte (BAUMAN, 2008, p. 45). A certeza de a morte ser algo inevitável e irreversível potencializa o medo, e faz com que o adulto rejeite a ideia de que morte seja um assunto a ser tratado pelas crianças. Lotterman (2010) aponta que ao longo do último século nas sociedades industrializadas do ocidente, as crianças passaram a ser vistas como seres frágeis que não deveriam ter contato com a morte. Assim, por muito tempo permaneceu a ideia de afastar a morte das crianças, com o intuito de protegê-las do sofrimento.

Entretanto, ao mesmo tempo que causa perturbações e medos, pensar e compreender a morte é um ponto fulcral para o entendimento do que é ser humano. Segundo Philippe Ariès (2003, p. 58), "A morte tornou-se o lugar em que o homem melhor tomou consciência de si mesmo", ou seja, ao refletir sobre a nossa finitude, refletimos sobre os sentidos da vida e assim, temos como buscar viver em plenitude. A certeza da morte que faz com que a vida seja um valor em si mesma - em outras palavras a consciência da finitude é o que nos faz humanos, pois temos a necessidade de aproveitar nossa existência e assumimos como missão deixar algo para a posteridade.

Nessa perspectiva, não há como proteger as crianças do conceito de morte, pois estamos cercados pela morte e suas representações. Dessa forma, trazer a morte para o convívio das crianças nada mais é do que restaurar sua dimensão humana - reconhecendo assim que a morte é uma etapa do ciclo da vida (LOTTERMAN, 2010).

A literatura infantil brasileira está consolidada e, portanto, há uma abertura para que autores e obras dialoguem diretamente com inúmeras temáticas, inclusive com temas fraturantes e considerados como tabus, como a morte. Entretanto, a morte como tema e parte do enredo de narrativas infantis sempre suscita alguns questionamentos:

Como o tratamento dado à morte em uma obra destinada às crianças torna-se assunto delicado em função da imaturidade de seus destinatários, surge a pergunta: como falar às crianças sobre um tema complexo sem adotar uma postura didática, pedagogizante? Ou melhor, como manter o padrão de esteticidade próprio de uma obra de arte literária e ao mesmo tempo atender às condições específicas de recepção do leitor infantil? (DUARTE, 1997, p.88). 
As questões levantadas são relevantes, pois adultos tem dificuldade em processar a ideia o medo da morte, então, a temática apresentada para crianças sempre correrá o risco de ser ou superficial, ou atrelada a um contexto moralizante. Entretanto, Josué Guimarães em A última bruxa, escapa das possíveis armadilhas, pois consegue abordar a temática da morte evitando qualquer postura moralizante, didática ou até mesmo óbvia.

Se por um lado, a partir da análise, podemos considerar que as dicotomias morte $\mathrm{x}$ vida, fim $\mathrm{x}$ recomeço são fundamentais para a compreensão da narrativa, também é possível afirmar que elas não se opõem, ou seja, não é como uma carga negativa se opondo a uma carga positiva. Não é como se a morte de Vovozinha, o fim da sua existência, representasse algo ruim. $\mathrm{O}$ medo original provocado pela sombra da morte (BAUMAN, 2008) não é o conflito principal. Vovozinha vira pó e em nenhum momento da narrativa há uma preocupação ou revolta em relação a isso. Simplesmente é apresentado uma informação geral sobre o ciclo normal da vida de uma bruxa: todas as bruxas, em determinado ponto da vida, começam a secar, murchar até virar pó que é levado pelo vento. $\mathrm{O}$ que traz o tom de emergência e o conflito para a história é o fato de a vida de Vovozinha não ter sentido - a personagem se angustia por não ter poderes mágicos e assim não ter meios para construir o seu legado.

Em outras palavras, Vovozinha passou a vida sem viver plenamente, sem conhecer e vivenciar a própria identidade. Assim, quando a personagem consegue descobrir a sua magia e tem a coragem de sair da torre e descobrir o mundo, ela encontra o sentido da sua vida e pode ressignificar a sua existência. Assim, sua morte tem uma ampla relação com a vida, já que a verruga, símbolo da continuidade da magia é transferida para uma nova vida. O fim não é um fim em si mesmo, mas uma nova possibilidade de recomeço. Assim, Vovozinha torna-se pó e é levada pelo vento, a narrativa não termina de forma melancólica ou triste, pois Vovozinha consegue transferir sua magia, consegue deixar uma herança e sua marca no mundo. A marca na permanência da magia, apesar da morte.

Interessante pontuar que todas essas reflexões sobre vida, morte, o sentido da existência que ecoam a partir da narrativa de Josué Guimarães não necessariamente serão ou precisam ser plenamente compreendidos pelos leitores infantis. A primeira leitura - a história de uma bruxa atrapalhada que não sabe fazer bruxaria - é atrativa o suficiente para o leitor infantil. $\mathrm{O}$ fato de existirem outras camadas e outros aprofundamentos no texto de Josué, só reafirmam a qualidade de sua literatura, e de como uma obra endereçada para crianças tem tanto a 
dizer para qualquer pessoa, independentemente da idade.

\section{Considerações finais}

O presente artigo apresentou três possibilidades de interpretação da obra $A$ última Bruxa; uma alinhada às vivências e experiências das crianças - e assim, a história é lida observando a intertextualidade com os contos de fadas e sua reinterpretação. Outra que leva em conta o contexto de produção e assim a obra pode ser lida como uma analogia para a abertura democrática brasileira no final dos 1980 - interpretação que leva em conta a atuação engajada e atenta ao contexto político que Josué Guimarães sempre apresentou em sua obra. E finalmente, uma terceira leitura, que compreende as referências à magia como metáforas para a própria existência humana na Terra - e assim "A última Bruxa" é uma aguda narrativa sobre o sentido da vida.

Importante apontar que as três possibilidades de leitura não se anulam, pelo contrário, potencializam a força da narrativa e ampliam sua potência enquanto obra literária. Reconhecer as referências, alusões aos contos de fadas e a forma que são reconduzidos, não impede de reconhecer à possibilidade de uma analogia com a realidade brasileira e nem a constatação que a morte é um fio condutor de destaque na leitura da obra. São camadas que se somam e permitem a construção de inúmeros cruzamentos interpretativos. Da mesma forma, não esgotamos outras possíveis leituras e outras abertura interpretativas que a obra possa apresentar.

A partir do exposto, consideramos $A$ última Bruxa como uma obra que dialoga e nos faz pensar sobre legados e heranças - a vida de Vovozinha passa a ter sentido quando ela consegue transmitir e preservar a magia do mundo, garantindo que ela permaneça, mesmo após ela ser levada pela ventania. Curioso perceber que foi uma das últimas obras escritas por Josué Guimarães, um autor que sem dúvida nenhuma, continua a existir, resistir e inspirar leitores muitos anos após a sua morte, pois o seu sopro de vida permanece eterno em sua obra literária.

Representations of Death and the Restart in Children's Literature by Josué Guimarães

\section{Abstract}

A última bruxa (The last witch), an instigating and provocative children's book by Josué Guimarães, was published in 1987. Through the mobilization of the witch figure, Guimarães creates a story that dialogues with concepts such as death, life, eternity, old age and new beginnings. The objective of this work is to analyze the book cited, realizing how the dichotomies death $\mathrm{x}$ life, end $\mathrm{x}$ beginning are fundamental for the understanding of the narrative. We defend in this work that the work presents 
three possibilities of interpretation; one aligned with the experiences of the child reader - and thus, the story will be a reinterpretation of fairy tales. Another one that takes into account the production context and thus the book can be read as an analogy for the Brazilian democratic opening in the late 1980s. And finally, a third reading, which understands references to magic as metaphors for human existence itself in the Earth - and thus A última bruxa is an acute narrative about the meaning of life.

Keywords: Children's Literature. Josué Guimarães. Witch. Death.

\section{Referências}

AGUIAR, Vera Teixeira. A conquista do leitor infantil. In: REMÉDIOS, Maria Luiza. Josué Guimarães: o autor e sua ficção. Porto Alegre: Ed. Univ. UFRGS, 1997.

ARIÉS, Philippe. História da Morte no Ocidente. Trad. Priscila Viana de Siqueira. Rio de Janeiro: Ediouro, 2003.

BAUMAN, Zygmunt. Medo líquido. Rio de Janeiro: Jorge Zahar, 2008.

CHEVALIER, Jean; GHEERBRANT, Alain. Dicionário de símbolos: (mitos, sonhos, costumes, gestos, formas, figuras, cores, números). Trad. Vera da Costa e Silva [et al.]. 21. ed. Rio de Janeiro: José Olympio, 2012.

COELHO, Nelly Novaes. Literatura infantil: teoria, análise, didática. São Paulo: Moderna, 2000 .

DUARTE, Lia Cupertino. A Morte - Seu sentido e sua expressão em narrativas infantojuvenis. (mestrado) Universidade Estadual Paulista - Campus de São José do Rio Preto, 1997.
HUNT, Peter. Crítica, teoria e Literatura infantil. Trad. Cid Knipel. São Paulo: Cosac Naify, 2010.

GUIMARÃES, Josué. A última bruxa. Porto Alegre: L\&PM, 1986.

JACOBY, Sissa, A bruxa no imaginário infantil: A última bruxa de Josué Guimarães, Letras de Hoje, Porto Alegre, v. 44, n. 4, p. 86-91, out./dez. 2009.

LOTTERMANN, Clarice. Escrever para armazenar o tempo: morte e arte na obra de Lygia Bojunga. Cascavel: Edunioeste, 2010.

RETTENMAIER, Miguel; REMÉDIOS, Maria Luíza Ritzel. Josué Guimarães, um revisor da história. Revista Desenredo, Passo Fundo, v. 2, n. 1, 2006.

RETTENMAIER, Miguel; VERARDI, Fabiane. Tempo de ausência: 30 anos sem Josué. Passo Fundo: EDIUPF, 2019.

ZORDAN, Paola Basso M. B. Gomes. Bruxas: figuras de poder. Revista Estudos Feministas, Florianópolis, v. 13, n. 2, maio-agosto, p. 331-341, 2005. 